CBIE-LACLO 2015

Anais do XXI Workshop de Informática na Escola (WIE 2015)

\title{
Socialização do ensino em mídia social na internet: configurações identitárias e representações constituídas
}

\author{
Elaine Alves Testoni ${ }^{1}$, Sílvia Cristina Dotta $^{2}$ \\ ${ }^{1}$ Programa de Pós-Graduação em Ciências Humanas e Sociais - Universidade Federal do \\ ABC (UFABC) Avenida dos Estados, 5001 - CEP 09210-580 - Santo André - SP - Brazil \\ ${ }^{2}$ Centro de Matemática, Computação e Cognição - Universidade Federal do ABC (UFABC) \\ Avenida dos Estados, 5001 - CEP 09210-580 - Santo André - SP - Brazil \\ elaine.testoni@ufabc.edu.br, silvia.dotta@ufabc.edu.br
}

\begin{abstract}
This paper aims to investigate the socialization of social media education indicating the relevance of identities and social representations students for the promotion of learning. In this sense, the object of analysis corresponds to a structured didactic activity on Facebook, as a resource to analyze the pedagogical socialization of students outside the university space. Thus, we will analyze the sociability of manifestations of students through practical experience, in which the teacher proposes to students a debate about particular movie. The expected results constitute the teaching socialization in social media as a significant resource for the construction of knowledge.
\end{abstract}

Resumo. $O$ objetivo deste artigo é investigar a socialização do ensino em mídia social apontando a relevância das identidades e das representações sociais discentes para o fomento da aprendizagem. Nesse sentido, o objeto de análise compreende uma atividade didática estruturada no Facebook, como forma de verificar a socialização pedagógica de universitários em um espaço exterior à universidade. Dessa maneira, serão analisadas manifestações de sociabilidade dos interlocutores por meio de uma experiência prática, na qual a docente propõe aos alunos um debate acerca de dado filme. Os resultados esperados configuram a socialização didática em mídia social como recurso significativo para a construção do conhecimento.

\section{Introdução}

As mídias sociais na internet abarcam fatores que compreendem a correlação entre aspectos humanos em um dado grupo social e elementos tecnológicos digitais capazes de tornar possível a organização e interação mediatizada, promotora de sociabilidade [Dotta, 2011]. A conexão entre os atores de grupos sociais distintos projeta fluxos de informações e demanda colaboração mútua na interação comunicacional dos membros participantes, assim sendo, articulam-se os saberes a partir da troca de experiências socialmente compartilhadas. 
CBIE-LACLO 2015

Anais do XXI Workshop de Informática na Escola (WIE 2015)

Por conseguinte, a socialização potencializa as percepções do indivíduo na interação com o espaço no qual se insere e fortalece suas habilidades analíticas e reflexivas ao passo que sistematiza, interpreta e compartilha as informações disponíveis [Setton, 2002]. Assim, o fazer social admite perspectivas quanto à constituição identitária dos indivíduos e nutre seus papéis socioculturais no âmbito educacional tendo a mídia como instância socializadora.

A identidade é a caracterização de indivíduos que organizam seu significado a partir de suas ações, sem deixar de lado o que são ou acreditam que são [Castells, 1999]. Dessa maneira, cabe refletir a construção identitária como um procedimento ativo e inconcluso, visto que o indivíduo assinala suas impressões de acordo com a esfera social que dialoga e com os atores sociais que fazem parte do seu entorno [Hall, 2014].

Diante disso, justificamos a escolha do tema em virtude do interesse em perceber a ocorrência da socialização didática em mídia social na internet como recurso favorável para o processo de ensino-aprendizagem, destacando a influência das identidades e das representações sociais como aporte significativo para a construção cognitiva. Logo, o objetivo deste trabalho é investigar a socialização do ensino em mídia social apontando a relevância das identidades e das representações sociais discentes para a edificação do conhecimento.

O problema diz respeito aos fatores essenciais que justificam a influência da socialização nos procedimentos didáticos para a apreensão dos saberes. Depreende-se, para tanto, alguns questionamentos relativos à análise: de que forma a socialização do ensino em mídia social pode propiciar o estímulo discente para a construção do conhecimento? Como as identidades influenciam nas interações socioculturais? Como as representações sociais podem contribuir para a aprendizagem socializadora?

As hipóteses são que a socialização didática em mídia social fomenta as posições problematizantes que levam à constituição cognitiva, uma vez que assegura um espaço não usual, mas colaborativo e instigante de procedimentos didáticos em que a troca de informações mediadas pela internet torna-se mais atraente para os estudantes. As identidades, por sua vez, revelam significações e sentidos a partir de projeções simbólicas que aproximam o indivíduo da sociedade. Quanto às representações sociais, há uma ocorrência de articulações representativas percebidas nas abordagens comunicacionais que convergem para a aproximação interacional e facilita a socialização do conhecimento.

As premissas metodológicas incluem a pesquisa exploratória, tendo como objeto de investigação uma atividade didática publicada no Facebook a fim de estimular interesses acadêmicos fora do espaço universitário. Pressupõem ainda análises teóricas firmadas, entre outras possibilidades, nos estudos desenvolvidos por Dotta (2011), Hall (2000, 2014), Jodelet (1993) e Setton (2002), conforme veremos na seção de metodologia.

Os encadeamentos discursivos que versaremos neste trabalho circundam as correspondências sociais e os reflexos destas ações no processo de ensino-aprendizagem em mídia social na internet.

\section{Socialização e identidade: relações significantes para a apreensão cognitiva}


CBIE-LACLO 2015

Anais do XXI Workshop de Informática na Escola (WIE 2015)

A socialização como processo nos leva a refletir sobre o papel das instituições sociais e a articulação dos indivíduos que englobam tais esferas [Setton, 2002]. Notamos, com interesse particular no âmbito educacional, a influência da cultura na formação dos discentes, uma vez que destaca característica relevante na interação coletiva incorporando estilos e ações de um grupo a partir de valores, preceitos morais e condutas de ordem social que imprimem no indivíduo, traços singulares capazes de institui-lo como ser socialmente identificável.

No panorama socialmente constituído, sociedade e indivíduo exprimem posturas divergentes, mas criam um elo de dependência quando indivíduos passam a se identificar com valores sociais [Setton, 2002]. Assim sendo, a construção social da realidade abarca vestígios socioculturais e permite projetar a socialização por meio das mudanças sociais adquiridas.

Ao tratarmos sobre as relações de ensino em mídia social e a socialização no ambiente subsidiado pela internet para estes fins, podemos resgatar as considerações apontadas por Giddens (1994), quando defende as dimensões transformadoras do âmbito social a partir de uma ressignificação do tempo e do espaço entre pessoas distanciadas. Nessa perspectiva, as práxis didáticas podem enveredar de maneira difusa no dia a dia das relações em sociedade e contribuir para a apreensão do conhecimento e socialização de identidades actoriais.

A identidade atribuída ao sujeito social apresenta características que demonstram a complexidade do mundo moderno e o compartilhamento interativo do eu com um mundo público. Tais experiências são oriundas de significados, sentidos, cultura, projeções simbólicas que evidenciam a conexão entre o $e u$ e a sociedade. Esta conexão expressa diálogo constante com espaços culturais externos e a relação identitária que tais espaços propiciam [Setton, 2002].

Ao traspormos nossas identidades culturais partilhamos valores e absorvemos atributos externos que nos levam a ocupar novos espaços socioculturais. Desse modo, a identidade entrelaça o indivíduo a uma estrutura societária, que quando pensada em educação em mídia social excede a conduta de unificação da identidade e vincula-se a diversas identidades, nem sempre convergentes.

As transformações culturais sofridas ao longo dos tempos instauram novas formas de interação entre indivíduo e sociedade e nos permitem expor indicadores que levam o homem a refletir sobre o seu desempenho social e os desdobramentos de suas atitudes como reflexo na atitude alheia. Nesse ínterim, cabe lembrar que o conceito de cultura tratado por Hall (2000) ocupa um sentido especificamente particular quando comparado às noções de cultura utilizadas nas abordagens antropológicas. As revoluções culturais admitidas pela sociedade no decorrer dos tempos refletem a abrangência da cultura que se propaga, de maneira significativa, nos dias de hoje e repercute de forma direta na identidade do ator social (HALL, 2000).

A identidade como formação mutável se projeta continuamente nas estruturas sociais que nos representam e também por meio de manifestações culturais que nos cercam. Conforme as significações e as representações culturais são propagadas, somos assolados 
CBIE-LACLO 2015

Anais do XXI Workshop de Informática na Escola (WIE 2015)

por uma variedade expressiva de prováveis identidades cuja identificação poderia ocorrer, pelo menos, em projeção efêmera.

\section{Representações sociais: influências valorativas na construção dos saberes}

A interatividade com o mundo que nos cerca permite adequação a situações e circunstâncias distintas, envolvimento com propósitos pessoais e coletivos, reconhecimento de posturas individuais e de outrem, localização espacial e intelectual, identificação e resolução de problemas. Características estas que integram as representações no meio social cotidiano [Jodelet, 1993].

A relação com outros indivíduos cria uma espécie de conexão, ora convergente, ora divergente, resultante do desempenho humano em constante transformação e caracteriza representações indispensáveis à vida social. As representações se consolidam no espaço socialmente construído mediante uma gama de enfoques da nossa realidade que podem ser atribuídos a interpretações, determinações, posicionamentos, atitudes e percebidos nas projeções discursivas e representativas das linguagens.

As instâncias cognitivas são uma importante representação social que, por sua vez, propaga valores em grupos sociais cujas significações apreendidas dialogam com saberes previamente construídos e resgatados em contextos sociais específicos. Contemplam elementos de natureza ideológica, histórica, cultural e abrangem um universo de conhecimentos científicos, manifestações empíricas da sociedade e traços de experiências individuais.

Conforme Jodelet (1993), a representatividade também pode ocorrer pelas conexões em redes sociais, uma vez que no processo comunicacional são admitidos elementos representativos da linguagem como possíveis influências em diferentes formas de persuasão e manipulação. Assim, ao considerar tais aspectos direcionados ao ensino em mídia social na internet notamos que o compartilhamento de dados, por elementos de um mesmo grupo, abrangem significações variadas de características que exprimem dada realidade.

Nessa perspectiva, o espaço educacional promove a edificação da aprendizagem a partir da interação colaborativa, da autonomia de atitudes, do desenvolvimento de habilidades e de competências discentes, do poder crítico e reflexivo sobre as manifestações em sociedade [Santos, Schwarzelmüller e Lima, 2012]. Em tal espaço, as representações são reproduzidas a partir de encadeamentos lógicos de ideias, experiências, posicionamentos, posturas e ações interconectadas a um propósito comum.

\section{Metodologia}

O instrumento de averiguação, objeto desta análise, diz respeito a uma atividade didática sistematizada no Facebook, proposta pela disciplina Projeto Dirigido e direcionada a alunos de graduação da Universidade Federal do ABC, no ano de 2014. A disciplina objetiva formar os alunos para a elaboração de projetos de pesquisa científica. O direcionamento da atividade didática na mídia social tem como finalidade propiciar interação acadêmica fora do espaço universitário, levar os alunos a refletirem sobre as inúmeras possibilidades 
metodológicas para a condução de uma pesquisa e a importância de seguir o método científico para se atingir objetivos de pesquisa.

A atividade corresponde a um debate estimulado a partir de abordagens provenientes do contexto disciplinar, sobre o filme "Memento" (título original), gênero drama/suspense, dirigido por Christopher Nolan (2000). O filme conta a história de um jovem rapaz que tem a esposa assassinada de modo violento e sai em busca do possível criminoso. Todavia, o impacto brutal da tragédia deixa uma sequela: ele perde a memória de curto prazo - fato que o leva a guardar informações apenas por pequenos espaços de tempo. Para conseguir manter-se conectado às circunstâncias do presente a fim de descobrir o assassino, o protagonista desenvolve uma metodologia de fazer fotos instantâneas, anotar informações nessas fotos e tatuar no próprio corpo, dados essenciais para seus objetivos.

A estrutura da atividade consolida um debate que favorece o reconhecimento de marcas identitárias expressas na socialização dos alunos e se fundamenta em interesses educacionais que se mostram pelas argumentações persuasivas dos prós ou dos contra nas circunstâncias a serem discutidas. Diante disso, a mediação se nutre do apoio da docente responsável por apresentar a finalidade do estudo, evidenciar a focalização do assunto, explanar os procedimentos de pesquisa, designar o prazo de postagem e sugerir correlações dinâmicas instituídas de apreciações cabíveis e significativas.

Alicerçada nessa lógica, a docente (D) apresenta as instruções necessárias para o desenvolvimento da atividade. Em seguida, os estudantes (E) se organizam em torno das apreciações relativas ao texto e sistematizam a dinâmica com base em exposições reflexivas, réplicas e tréplicas oriundas do propósito contextual. Delineada a apresentação da estrutura que organiza o debate, o quadro 1 explicita as orientações da docente para a atividade.

\section{Quadro 1. Orientações da docente para a atividade}

\section{D - 27 mar. 2014, às 10h57}

Esta atividade deve ser realizada até às $23 \mathrm{~h}$ do dia 13/04.

Assistir ao filme "Memento" [Christopher Nolan, 2000].

Ao assistir ao filme "Memento", procure identificar:

Objetivo (de pesquisa) do protagonista.

Problema da pesquisa, hipótese, justificativa, contextualização.

Referenciais (teóricos) utilizados pelo protagonista para analisar seus achados.

Metodologia (de pesquisa) adotada pelo protagonista para realizar sua pesquisa.

Participar de discussões do grupo do Facebook.

1. Primeiro POST: Reflita e procure responder.

Qual sua opinião sobre o filme?

Procure explicitar o objetivo, problema, hipótese, referenciais etc. Em seguida faça uma reflexão: o protagonista atingiu seu objetivo de pesquisa? Corroborou suas hipóteses? Os referenciais foram adequados para a realização da pesquisa? Os métodos foram adequados e/ou suficientes para a conclusão da pesquisa?

2. RÉPLICA: Em seguida, localize ao menos uma participação de um colega cujas ideias sejam contrárias às suas (com quem você discorde) e argumente explicitando os pontos da discordância e sua justificativa.

3. TRÉPLICA: Selecione ao menos um comentário de seus colegas a respeito de sua opinião inicial e contraargumente, ou reconstrua seus argumentos iniciais. 
Tendo em vista preservar a identidade dos estudantes (E), os quatro componentes de um determinado grupo, escolhidos para compor esta análise, serão identificados pela numeração equivalente de 1 a 4, sendo reconhecidos pelas abreviações descritas como E1, E2, E3 e E4.

\section{Análise dos resultados alcançados}

O procedimento interacional dos alunos, resultante das práticas educativas ofertadas no Facebook, compreende circunstância oportuna para a percepção do ensino como proposta socializadora fora do ambiente universitário. A conduta docente estimula a expressão discursiva na qual os estudantes deixam transparecer vestígios das suas identidades. Identidades estas que revelam traços do desenvolvimento de cada um e, somados às identidades conjuntas, ilustram a formação do conhecimento coletivo.

A identidade, por este ângulo entrelaça dois caminhos. Um, relativo aos discursos e práticas correspondentes às nossas ações como sujeitos sociais e outro, condizente aos procedimentos que manifestam ideias, posturas, predileções e características individuais expressas na construção do sujeito social. "As identidades são, pois ponto de apego temporário às posições de sujeito que as práticas discursivas constroem para nós" [Hall, 2000, p. 111].

As proposições apontadas no quadro 2 demonstram condutas socializadoras e fomentam o encadeamento participativo dos estudantes a começar de um ponto de vista que estimula os argumentos inerentes ao debate.

\section{Quadro 2. Socialização do estudante - E1}

E1 - 13 abr. 2014, às 17h32

O objetivo que permeia a trama é de o protagonista encontrar o assassino de sua esposa e matá-lo. Umas das grandes problemáticas do enredo é de que protagonista sofre de um transtorno de perda de memória recente, o que o dificulta bastante para atingir seu objetivo. A Justificativa, em suma, está contida no desejo de vingança de Leonard para encontrar o verdadeiro assassino de sua esposa e fazer justiça pelo ocorrido. Quanto a metodologia usada para atingir seu objetivo pode-se destacar as anotações, fotografias e tatuagens feitas em sua pele para se lembrar dos fatos.

De certa forma, em minha opinião, ele alcançou o seu objetivo inicial no sentido de que de alguma forma se vingou e em sua cabeça fez justiça pelo assassinato de sua esposa, apesar de todas as manipulações que sofreu.

No quadro 2, E1 demonstra habilidade de argumentação explorada no contexto narrativo e assegura um tipo de representação linguística que ganha impulso em virtude da estratégia persuasiva e do esforço na tentativa de manipular o outro, induzindo-o a acreditar em dados, rever posturas, confrontar opiniões ou fazer o que se deseja.

Contudo, o posicionamento de E2 é divergente e nos leva a observar outro perfil marcado por traços de identidade deste estudante, como apontado no quadro 3.

\section{Quadro 3. Socialização do estudante - E2}

\section{E2 - 13 abr. 2014, às $17 \mathrm{~h} 45$}

Discordo de sua opinião no sentido de que não é possível concluir se realmente Leonard matou a pessoa certa ou todos os assassinatos que cometeu não foi por manipulação de Teddy. Durante o filme, todos os 
CBIE-LACLO 2015

Anais do XXI Workshop de Informática na Escola (WIE 2015)

assassinatos cometidos pelo protagonista não nos levam a crer que ele tenha matado a pessoa certa, mas sim que manipulou as pistas para encontrar e matar alguém.

E2 defende a manipulação do protagonista e objeto da atividade, e nessa defesa, valida certo delineamento do seu perfil individual convergente com fatores propagados no espaço coletivo, dos quais ele acredita.

O fato de não ocupar posicionamentos equivalentes no cenário social, o indivíduo vivencia experiências nem sempre harmônicas. Assim, ele se pluraliza enquanto tangencia experiências de socialização em circunstâncias sociais múltiplas [Lahire, 2002].

A tréplica de E1 o assegura de sua convicção, como descrita no quadro 4.

\section{Quadro 4. Socialização do estudante - E1}

\section{E1 - 13 abr. 2014, às 17h49}

Até entendo seu ponto de vista de ter matado um possível inocente sob manipulação de Teddy. Mas ainda tenho convicção de que o objetivo de Leonard tenha sido alcançado, pois ele de alguma forma obteve o sentimento de vingança.

As alegações e as ideias expressas na linguagem surgem no confronto de pensamentos, posturas e ações entre os sujeitos atuantes que negociam sentidos na disposição comunicativa.

E1 reporta seu posicionamento sobre a personagem principal do filme e não há uma receptividade positiva por parte de E2, que diverge das impressões constatadas pelo interlocutor, não conferindo uniformidade avaliativa. Parte disso o fato de que a socialização articula posições distintas e viabiliza o livre acesso às escolhas. No caso de E2, a réplica traduz um exame de foco diverso sobre o contexto e projeta enunciados promotores de significância em outra direção.

Neste caso, notamos o emprego dos sentidos revelado pelos conhecimentos adquiridos e pelo discernimento da circunstância comunicativa de cada atuação no discurso. Sendo assim, apesar de E1 entender, de maneira sutil, o ponto de vista de E2, mantém-se condicionado às argumentações iniciais sem alterar seu parecer sobre os fatos.

O quadro 5 destaca um novo argumento para a apreciação de outros olhares referentes ao objeto de análise.

\section{Quadro 5. Socialização do estudante - E2}

\section{E2 - 13 abr. 2014, às 17h21}

O objetivo e Leonard, o protagonista do filme, é matar o responsável pela morte de sua esposa. Para tal ação utiliza como método anotações em seu corpo e em fotos que revelem as pistas para encontrar o assassino e o diga quem são as pessoas que estão a sua volta no momento e se elas podem ter alguma ligação com o assassinato.

O filme nos faz crer que Leonard tem uma hipótese falsa e segue pistas falsas muitas vezes criadas por sua imaginação devido a sua condição mental de esquecer fatos recentes, pois mesmo encontrando o verdadeiro assassino de sua esposa nunca iria ter certeza de que era ele.

Outra questão colocada é se realmente alguém assassinou sua esposa ou Leonard a matou.

Concluo então que como a hipótese é falsa (faz com que Leonard mate pessoas erradas) e como Leonard não sabe se sua esposa foi ou não assassinada o objetivo não pode ser dado como alcançado. 
E2 focaliza mais um detalhe sobre Leonard e assinala com firmeza a sua análise. O detalhe pode ser associado ao que Jodelet (1993, p. 5) explana sobre a imersão de símbolos como representações sociais. Para a autora, a representação é a "representante mental do objeto que reconstitui simbolicamente", desse modo, a menção de E2 acerca das tatuagens feitas pelo protagonista como anotações indicadoras de pistas corresponde a uma ativação da memória, responsável pela busca do símbolo. Este remete ao "caráter construtivo, criativo, autônomo da representação que comporta uma parte de reconstrução, de interpretação do objeto e de expressão do sujeito".

O desempenho analítico de E2 reproduz informações prováveis no que tange à apreensão contextual do enredo, focada na personagem protagonista. A certificação conclusiva das situações apontadas por este participante induz a uma possível manipulação. A defesa da ideia, no seu ponto de vista, é tão contundente que um novo post é inserido a fim de ratificar, com outro argumento, o parecer explicitado e compor uma nova intenção persuasiva, de acordo com o quadro 6.

\section{Quadro 6. Socialização do estudante - E2}

\section{E2 - 13 abr. 2014, às 17h49}

Acredito que o objetivo de Leonard seja mais do que saciar um desejo de vingança, mas sim fazer com que o verdadeiro culpado pela morte de sua esposa seja responsabilizado pelo que fez, ou não teria sentido raiva ao perceber que fora manipulado por Teddy para matar pessoas inocentes, de modo que não podemos concluir pelo filme que esse objetivo tenha sido alcançado.

O envolvimento de mais um ator destaca nova consideração sobre a trama, como demonstra o quadro 7.

\section{Quadro 7. Socialização do estudante - E3}

\section{E3 - 13 abr. 2014, às 17h54}

Discordo E1, pois acho que ele tem segurança do "erro" que está cometendo, mas concordo com você que ele alcançou o objetivo. E o desejo dele E2 era vingança sim, pois desde o "começo" do filme ele não mostrou interesse em entregar o assassino para a polícia, e sim matá-lo.

$\mathrm{O}$ post firmado por E3 percorre duas abordagens distintas. A primeira remete às posições de E1 em desacordo quanto à segurança do "erro" de Leonard e concordância sobre o alcance do objetivo dele. A segunda alude à opinião de E2 quando realça uma divergência acentuada de ideia a ponto de apresentar uma correção incisiva sobre o raciocínio deste.

O parecer de E3 no debate demonstra, conforme estudos baseados em Dotta (2011), a participação ativa e autônoma do indivíduo no ambiente sociointerativo bem como a liberdade de reflexão que concebe a este indivíduo a proficiência do diálogo, do questionamento e de escolhas diversas em uma dimensão de relações valorativas e diferentes dos demais.

No quadro 8, E4 integra o debate e corrobora a sua não concordância com E2.

\section{Quadro 8. Socialização do estudante - E4}

\section{E4 - 13 abr. 2014, às 19h40}


CBIE-LACLO 2015

Anais do XXI Workshop de Informática na Escola (WIE 2015)

Discordo com E2 no sentido de afirmar que a hipótese é falsa, pois apesar de em vários momentos do filme ser sugerida a existência de uma hipótese falsa, devido ao próprio problema do protagonista, fica difícil de afirmar com certeza se alguma hipótese era verdadeira ou falsa, haja vista que, mesmo com as declarações de Teddy, durante o filme, o mesmo mostrou-se de pouca confiança por ter se aproveitado do protagonista, assim como outros personagens fizeram.

A intervenção de E4 exibe o desagrado sobre o fato de E2 defender a hipótese como falsa, todavia percebemos no discurso certa dúvida sobre a veracidade ou não desta hipótese.

Ao examinarmos a atuação de E4 recorremos às concepções de Setton (2002) relativas à socialização, quando afirma que em contextos sociais distintos o indivíduo se encontra contínua e sincronicamente no cerne de uma variedade social heterogênea e se transforma dependendo da abordagem social que será impulsionado a levar em conta.

A linguagem reproduzida nos discursos dos estudantes evidenciam situações de sociabilidade manifestando representações identitárias. Estas se articulam por meio de recursos intelectivos e sociais incorporados ao conhecimento, à comunicação, às linguagens disponíveis e à interação socialmente construída no tocante às representações da realidade das quais elas participam [Jodelet, 1993].

\section{Considerações finais}

A atividade didática e colaborativa subsidiada pelo Facebook, neste contexto de análise, propiciou a socialização do ensino a partir de negociações coordenadas, das quais os métodos utilizados nos procedimentos discursivos favoreceram a troca de experiências e incitaram o desafio sucessivo de correlações entre perguntas e respostas.

Pudemos verificar que as identidades características dos perfis individuais discentes apresentaram atributos interpostos entre a realidade, de fato, e a interação particular de cada $e u$ com o mundo exterior. Estas experiências representaram significados, sentidos, valores, pontos de vista, projeções simbólicas capazes de evidenciar a conexão entre o eu e a sociedade. Assim, promoveram diálogo constante por meio de suas culturas, suas identidades e da realidade social em que estavam inseridos.

A partir das representações sociointerativas verificamos abordagens materiais, linguísticas e comportamentais que percorreram as esferas da comunicação entre os participantes destacando a relevância comunicacional e das linguagens nos fenômenos representativos. Além disso, as representações descortinaram signos ideológicos, históricos e culturais que se revelaram na constituição dos argumentos expressivos ao promover as desenvolturas em torno dos textos e do contexto didático.

A socialização do ensino praticada na mídia social permitiu expor ações críticas e reflexivas a partir de interpretações que se propagaram no ambiente de aprendizagem como um jogo de difusão de informações. Nesse jogo observamos as percepções dos interlocutores sobre si e sobre o grupo. Por esta razão, foi possível demonstrar formas variadas de alteridade, aproximando e afastando os atores sociais do cenário analítico. Nas alteridades, as características identitárias dos estudantes se consolidaram no debate e as 
representações provenientes de cada vivência foram esculpidas nos discursos promovendo e transformando saberes.

As constatações que apresentamos no decorrer desta análise permitiram corroborar as hipóteses sobre a relevância da socialização didática em mídia social para a apreensão cognitiva, os significados e os efeitos de sentidos nas inter-relações pessoais, a gama de representações que se propagam nos discursos e nas atitudes dos sujeitos socialmente constituídos favorecendo a alteridade entre os estudantes. Paralelamente a isso, nos facultou descrever a mídia social, neste estudo caracterizada pelo Facebook, como importante recurso para a propagação didático-pedagógica e para a construção do conhecimento.

\section{Referências}

Castells, Manuel. (1999) A sociedade em rede. Trad. Roneide Venancio Majer. 6. ed. São Paulo: Paz e Terra. (A era da informação: economia, sociedade e cultura; v.1).

Cortês, Norma. "Amnésia, o tempo como construção". Disponível em: http://www.espacoacademico.com.br/022/22ccortes.htm. Acesso em: 15 abr. 2014.

Dotta, Sílvia. (2011) Uso de uma Mídia Social como Ambiente Virtual de Aprendizagem. Anais do XXII SBIE - XVII WIE, Aracaju. Disponível em: http://www.brie.org/pub/index.php/sbie/article/view/1623/1388. Acesso em: 29 abr. 2015.

Giddens, Anthony. (1994) Modernidade e identidade pessoal. Oeiras, Celta.

Hall, Stuart. (2000) Quem precisa de identidade. In: Silva, Tomaz da (Org.) Identidade e diferença: a perspectiva dos Estudos Culturais. Petrópolis: Vozes.

Hall, Stuart. (2014) A identidade cultural na pós-modernidade. Trad. Tomaz Tadeu da Silva e Guacira Lopes Louro. Rio de Janeiro: DP\&A.

Jodelet, D. (1993) Représentations sociales: un domaine en expansion. In D. Jodelet (Ed.) Les représentations sociales. Paris: PUF, 1989, pp. 31-61. Tradução: Tarso Bonilha Mazzotti. UFRJ- Faculdade de Educação.

Lahire, Bernard. (2002) Homem plural: os determinantes da ação. Petrópolis: Vozes.

Santos, Debora Abdalla; Schwarzelmüller, Anna F; Lima, Amaleide. (2012) Projeto Educandow: experimentando uso de rede social como apoio ao ensino fundamental. Anais do XXIII SBIE, Rio de Janeiro. Disponível em: http://www.brie.org/index.php/anaissbie. Acesso em: 05 maio 2015.

Setton, Maria da Graça J. (2002) Família, escola e mídia: um campo com novas configurações. Educação e Pesquisa, Revista da Faculdade de Educação da USP, 28 (1): 107-116. 